\title{
Corporate efficiency improvement with business process automation
}

\author{
Robert Waszkowski ${ }^{1, *}$, Tadeusz Nowicki ${ }^{1}$ and Kazimierz Worwa ${ }^{1}$ \\ ${ }^{1}$ Military University of Technology, Faculty of Cybernetics, Urbanowicza 2, 00-908 Warsaw, Poland
}

\begin{abstract}
The paper outlines the concept for using the Business Process Management System (BPMS) to improve processes in a rental company. It also presents a case study of the implementation of the process approach in a medium-sized company dealing in the production, rental and service of work and protective clothing. The aim of the paper is to prepare reference business process models that allow you to measure and improve all the corporate activities. The process models were prepared in accordance with the BPMN (Business Process Model and Notation). The results of the conducted research prove that well designed business processes may not only be managed but also easily enhanced and automated in a way that allows organization to improve its performance in meaningful ways. The paper describes in detail - in subsequent chapters - sales, warehouse delivery, incoming correspondence handling, and cost accounting processes. In the last chapter the system architecture is presented. The proess models are prepared in an innovative way that allows easy process automation.
\end{abstract}

\section{Introduction}

The BPM, i.e. Business Process Management is more often a management concept in a given company than a complex IT system. However, it should be remembered that to increase the quality of the management process in a measurable manner, such complex IT systems are required and even indispensable in large companies. Therefore, more and more companies is interested in the implementation of the BPM tools [10].

The Business Process Management (BPM) refers to the management of business processes, i.a. via IT tools [1], [2], which allows managers to monitor completion of the process to produce better results. Since every business process is subject to management, BPM may be applied in all processes. In fact, it is most often used to build workflow systems in companies. Additionally, BPM is often applied in administrative, financial and customer service processes [4].

The BPM solutions are most frequently used to handle processes related to the document flow in companies, e.g. approval of purchase invoices or their equivalents, as well as internal documents, such as holiday request forms or business trips. Therefore, the systems are most likely to be successfully implemented in the public sector, in all shared service centres and large organizations regardless of the sector in which they operate [5], [3].

The article outlines a number of business processes designed for task automation in a rental company to improve its corporate efficiency.

\section{Business processes}

\subsection{Sales process}

The sales process allows an employee of customer service department or a key account manager to launch a new sales oportunity, which arises as a result of a request for quotation from a potential customer. The process covers all tasks performed in order to acquire a new client. The process is carried out in accordance with the following steps:

1. Customer data entry - based on an inquiry submitted by the client.

2. Verification of customer information and first contact with the client to arrange a meeting.

3. Familiarizing the client with the company's offer during the first meeting or a series of meetings.

4. Conducting audits at the client's and at the company's headquarters.

5. Performing reference visits.

6. Clarification of details and preparation of the offer.

7. Determination of the price by the CEO of the company.

8. Presentation of the price offer and contract drafts to the customer.

9. Negotiations with the client. The final decision about cooperation - Resignation from cooperation or Signing the contract.

The process is started using the appropriate button located on the Customer Service employee desktop or Key Account Manager desktop.

\footnotetext{
* Corresponding author: robert.waszkowski@,wat.edu.pl
} 


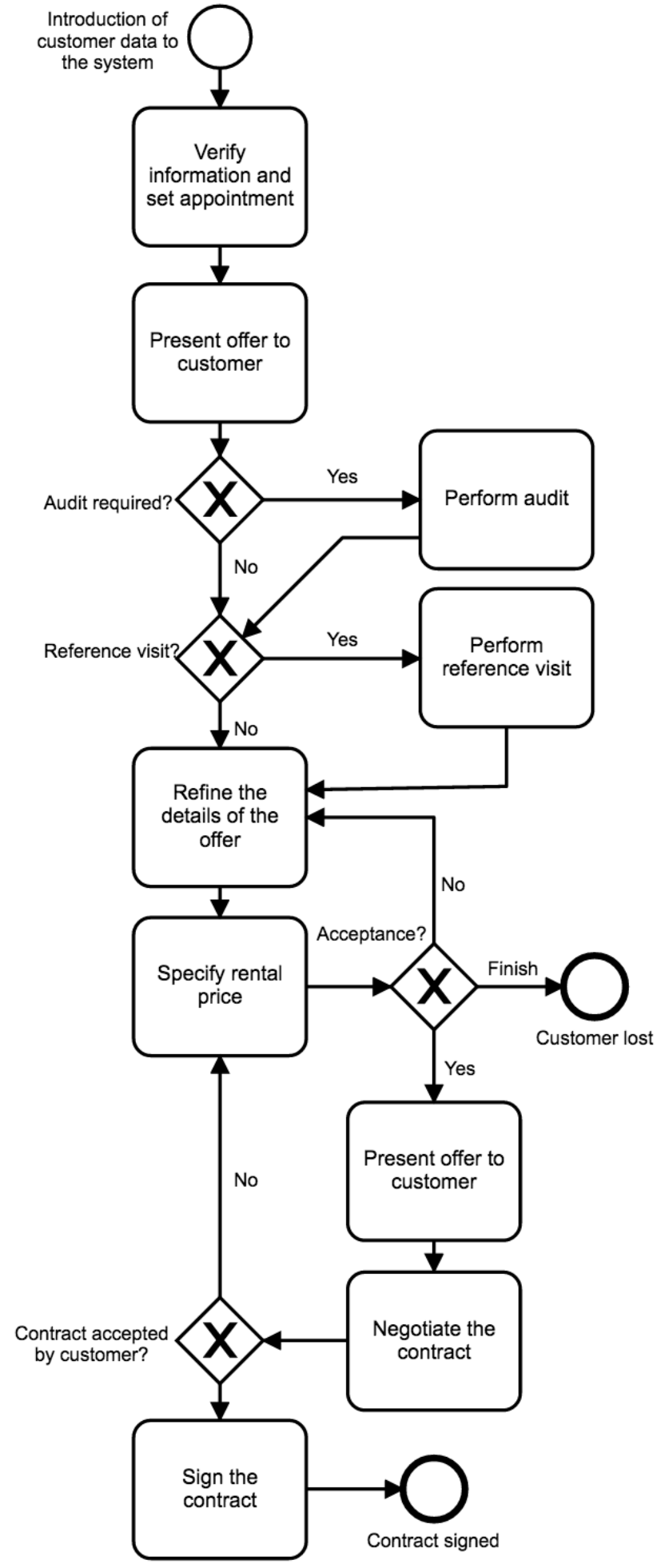

Fig. 1. Sales process diagram.

The start-up task allows you to launch a new sales oportunity. In order to launch a new sales process, a customer service employee or key account manager chooses the appropriate option from the menu, and then completes the form with customer data provided with the inquiry.

The task is run by an employee in the appropriate role (Customer Service or Key Account Manager) at the moment when it is necessary to launch a new sales oportunity.

Starting the process results in displaying a form containing customer data and operating elements.

Approving the completed form is tantamount to launching a new sales oportunity. After confirming the start-up task, the succeeding task is automatically started: Verify the information and set ppointment.

The Verify information and set appointment task allows you to verify customer information and determine the date of meeting with the client. The task is performed by a person assigned to the role of Key Account Manager.

The task is run automatically after confirming the process's start form and appears on the list of employees in the role of Key Account Manager.

Approving the completed form is tantamount to verifying the information and setting the date of the meeting with the client. After confirming the task, another task is automatically started: Present offer to customer.

The Present offer to customer task is carried out during the meeting with the client, on which the trader is to familiarize the customer with the company's offer. The task is carried out by a person assigned to the role of Key Account Manager.

The task is run automatically after confirming the task form Verify information and set appointment and appears on the list of employees in the role of Key Account Manager.

Handling the task results in displaying a form containing customer data, contract data and operational elements.

Approval of the completed form is tantamount to the completion of meetings related to familiarizing the customer with the company's offer. As part of this step, the key account manager can have more than one meeting. Each meeting is registered in the Meeting Register.

After confirming the task, another tasks are automatically started - Perform audit or Perform reference visit. The task Perform audit is triggered when there is a need for audits. The task Reference visit is run when there is no need to perform an audit and a reference visit needs to be performed.

If there is no need to carry out audits or reference visits, the process goes straight to the task Refine the details of the offer.

The Perform audit task is carried out by a person assigned to the role of Key Account Manager.

Approving the completed form is equivalent to completing the audit. As part of this task, the key account manager can have more than one audit meeting. Each meeting is registered in the meeting register.

After confirming the task, another task is automatically started - Perform reference visits or Refine the details of the offer.

The Perform reference visit task is triggered when there is a need for a reference visit. If it is not necessary, the task Refine the details of the offer is started. 
The Perform reference visit task is carried out by a person assigned to the role of Key Account Manager in case of a reference visit.

The task is run automatically after confirming the task form Present offer to customer or Perform audit.

Approving the completed form is equivalent to completing the reference visits stage. As part of this step, the key account manager may have more than one meeting necessary to conduct the reference visit. After confirming the task, another task is automatically started - Refine the details of the offer.

The Refine the details of the offer task is carried out by the person assigned to the role of Key Account Manager and aims to prepare the offer for the client and the initial quotation.

Approving the completed form is equivalent to preparing the offer and initial quotation. After confirming the task, another task is automatically started: Specify rental price.

The Specify rental price task is implemented by the CEO and is aimed at determining the price of the rental.

The task is run automatically after confirming the task form Refine the details of the offer. The task appears on the list of tasks of the company's CEO.

Approving the completed form is equivalent to determining the price of the rental. After confirming the task, another task is automatically started: Present offer to customer or Refine the details of the offer again. The process can also end here.

The Present offer to customer task is activated when the offer prepared by the key account manager and the decision to conduct further conversations with the client are approved.

The Refine the details of the offer task is activated when the CEO sends back the offer to be improved and refined by the key account manager.

Completion of the process carried out at the moment when in the course of negotiation talks the CEO decides that the cooperation with the client should be terminated.

The Present offer to customer task is carried out by the key account manager and aims to provide the customer with a price offer approved by the CEO and model contracts.

The task is run automatically after confirming the task form Specify rental price.

Approving the completed form is equivalent to presenting the customer with a price offer and contract drafts. After confirming the task, another task is automatically started: Negotiate the contract.

The Negotiate the contract task is carried out by the key account manager and is aimed at negotiating a contract with a client.

The task is run automatically after confirming the task form Present offer to customer.

After confirming the task, another task is automatically started: Sign the contract or Specify rental price.
The Sign the contract task is carried out, when, as a result of negotiations, the client agrees to the offer and wants to sign a contract.

The Specify rental price task is run when the client wants to make changes to the contract as a result of negotiations. Such changes should be presented to the CEO for re-evaluation.

The Sign the contract task is carried out by the key account manager and is aimed at signing a contract with the client.

The task is run automatically after confirming the Negotiate the contract task form.

Approving the completed form is equivalent to signing the contract with the client. After confirming the task, the process ends automatically.

\subsection{Warehouse delivery process}

In order to register a delivery, a warehouse employee starts the Warehouse delivery process.

After confirming the completed delivery form, the document is registered and goes to the Warehouse Delivery Register. The status is set for the document: Pending for quality and quantity acceptance.

The registered document is forwarded to the warehouse employee for the purpose of quality and quantity inspection.

The warehouse employee fills out the form in accordance with the guidelines. If the delivery proved to be in accordance with the delivery form, then the next task (Perform quality and quantity control of the delivery) appears in the task list for the Quality Assurance employee. The status is set for the document: Pending for qualitative acceptance.

If the delivery is inconsistent with the delivery form, then the Evaluate inconsistency task is carried out for the Purchasing Specialist. The delivery status is set to: Pending evaluation of inconsistency.

In order to perform quality control of the delivery, the quality assurance employee completes the process form. If the delivery proved to be in accordance with the delivery form, the process ends, and the goods are taken to the warehouse. The delivery status is set to: Completed.

If the delivery turned out to be inconsistent with the delivery form, then the Evaluate inconsistency task is carried out and sent to the purchasing specialist. The delivery status is set to: Pending evaluation of inconsistency.

In order to assess the delivery inconsistency, the purchasing specialist handles the Evaluate inconsistency task.

When evaluating inconsistency, the purchasing specialist decides whether the delivery will be accepted in whole or in part or whether the delivery will be rejected. If the delivery is accepted, the process ends, and the goods are taken to the warehouse. If the delivery is not accepted, the process is over, and the incompatibility or complaint is beeing resolved. 


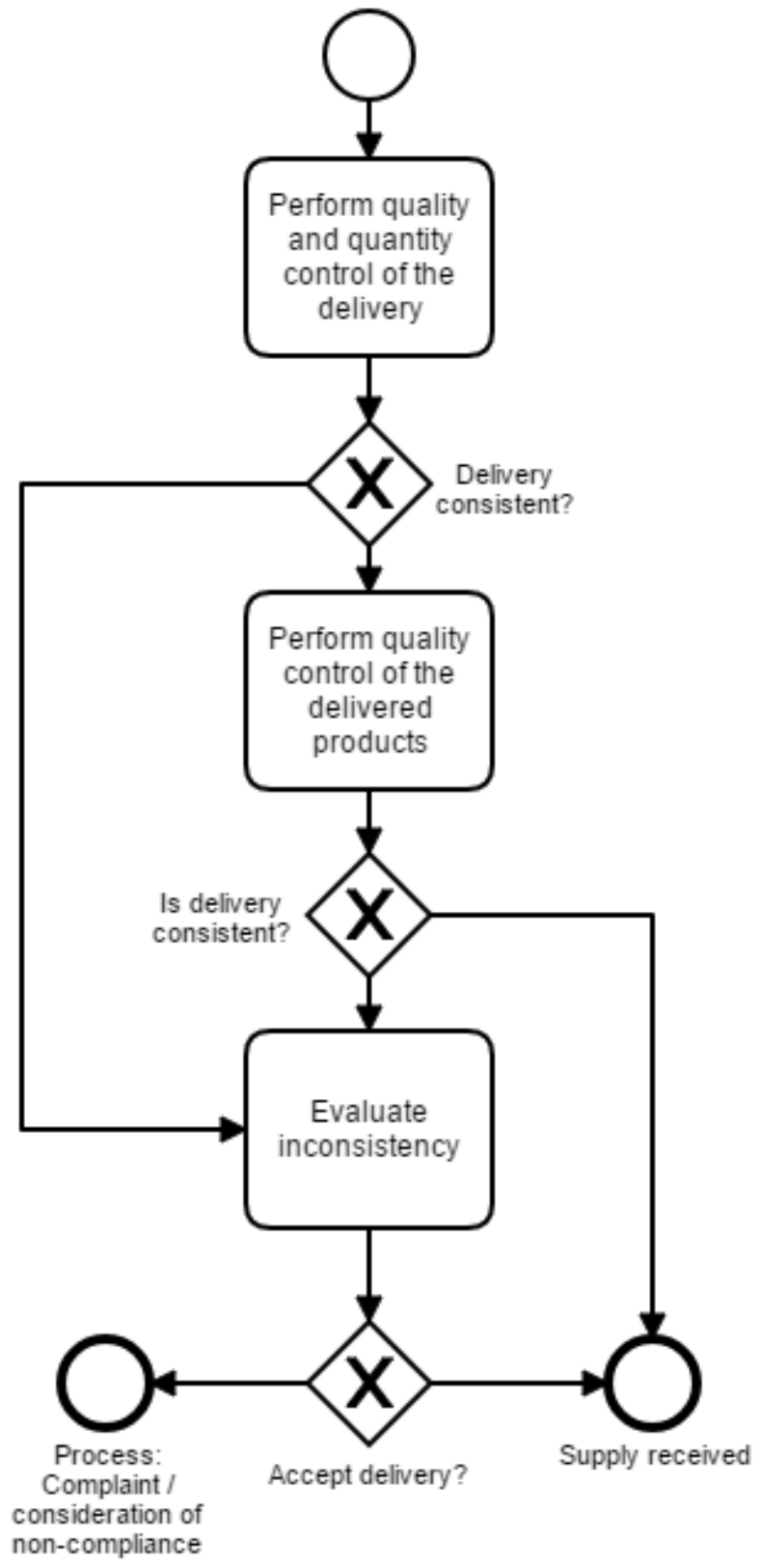

Fig. 2. Warehouse delivery process diagram.

\subsection{Incoming correspondence handling process}

The Incoming correspondence handling process allows the mailroom employee to enter the document metadata and register its electronic version to the system. Before the document is correctly registered in the system, the verification path passes. The document metadata are stored to the relevant register.

The start-up task allows you to register an incoming correspondence entering the office. In order to register the document, the mailroom employee completes the form with relevant data.

The task is run by the mailroom employee at the moment when it is necessary to register an incoming document.
Starting the process results in displaying a form consisting of the following sections:

- Registration details of the incoming document.

- Details of the sender of the document.

- Data of the recipient of the document.

Approving the completed form is equivalent to registering the document in the office.

Documents registered in the office are stored in the Registry of incomind corespondence with the appropriate status. After confirming the start-up task, another task is automatically started: Verify the document.

The Verify the document task allows you to verify the incoming document by the document's owner.

The task is run as the first step of the process after the registration of the document by the mailroom. The task is automatically forwarded to be handled by an employee who was proposed by the mailroom to be document's owner.

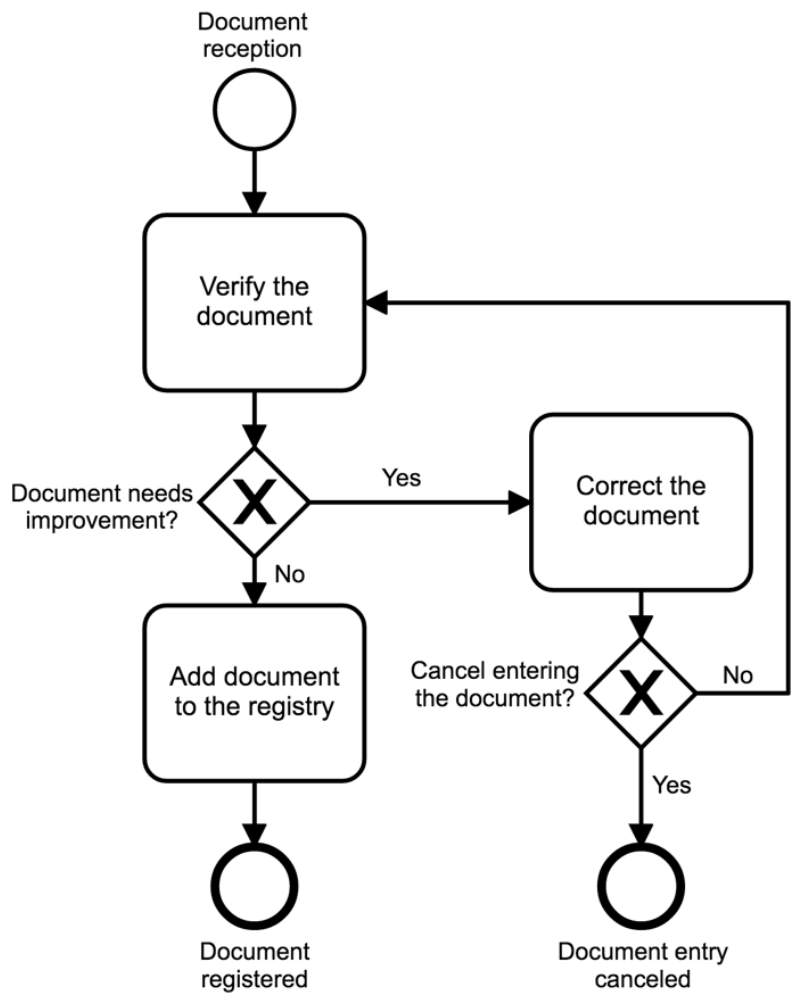

Fig. 3. Incoming correspondence handling process diagram.

The approval of the completed form is equivalent to the verification of the document by the owner.

After confirming the task form, another task is automatically started: Add document to the registry or Correct the document.

The Add document to the registry task is carried out when the document has been positively verified.

The Correct the document task is carried out when the owner sends back the document to be improved by the mailroom employee. 
The Add document to the registry task allows the mailroom employee to improve the document when the document is sent back for improvement by the owner.

The task is run only when the owner of the document sends back the document to be corrected.

Approving the completed form is equivalent to correcting the document or rejecting the document depending on the path chosen in the process. The approved task results in a change of status on the registry of office documents. The change in status in the registry is carried out regardless of whether the document is canceled or not. After confirming the task form, the Verify the document task is automatically run, or the process ends.

The Verify the document task is carried out when the mailroom corrects the document and sends it back for reverification by the owner.

The process ends when the document is canceled by the mailroom.

\subsection{Cost Accounting process}

The Cost Accounting process allows to indicate cost centers and the distribution of the cost objects (invoices) between these cost centers. In the first step, the registration and decree of the invoice is performed. Then the invoice is sent to the multi-stage acceptance. The first level of acceptance is to check the compliance of the received cost invoice with the order and to check the correctness of delivery with the cost invoice by persons designated for each cost center. In the next steps, the invoice goes to the approval of the financial department and, if necessary, to the board. The final stage is verification and accounting acceptance. Positively verified cost invoice is treated in the system as a posted document - sent to the ERP system and finally booked to individual accounts.

A start-up task allows you to register a cost document by the mailroom and to enforce the costs specified in the registered document.

Handling the task results in displaying a form containing the registration data of the document, seller data, cost invoice data, and operational cost allocation.

The approval of the completed form is equivalent to registering the document and determining of cost centers. The form can not be approved until all required fields have been filled out. The form can not be approved until the net sum of costs assigned to individual cost centers will not coincide with the overall document net cost value.

Approving the task takes you to the next step of the process: Checking the order. After approval, the registry entries are updated.

The Checking the order task allows you to read the cost document, verify whether the cost document corresponds to the order placed and to approve the cost sharing proposed by the mailroom employee.
The task is automatically placed on the task list of all users who are in the role of checking cost invoices. Each acceptor sees and decides only about the distribution of costs related to the cost center, for which he is responsible.

Approval of the completed form is equivalent to checking the cost invoice, confirming that it is compatible with the order and the acceptance of the cost assignation to appropriate cost centers. Confirmation of the task leads to the next step of the process: Improving the document or Checking delivery.

The Improving the document task is carried out at the moment when at least one cost center is not accepted.

The Checking delivery task is carried out when all cost center items are approved.

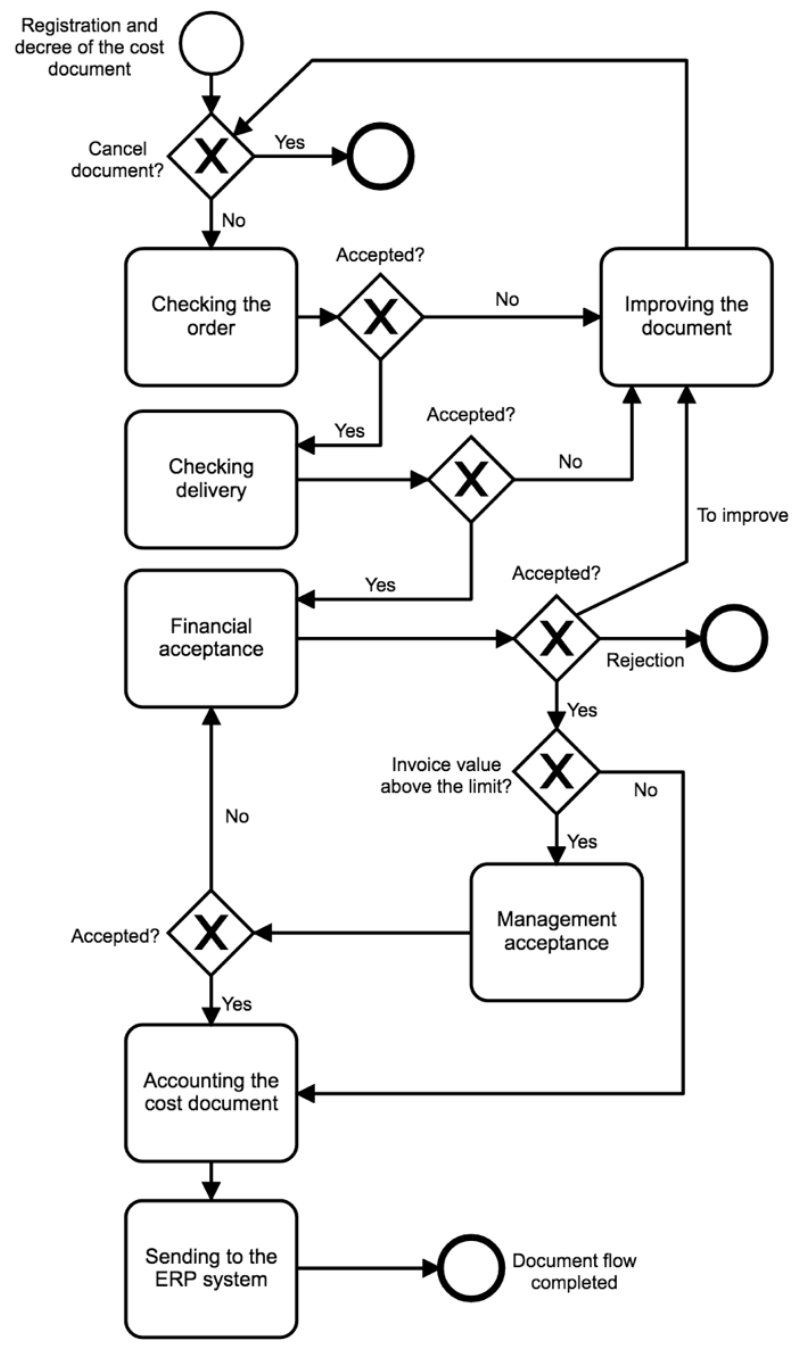

Fig. 4. Cost Accounting process diagram.

The Checking delivery task is to verify the correctness of delivery with the cost invoice received. The task is run only for invoices arriving with the delivery. In the case of prepayment to the account, the Checking delivery task is omitted. The task is automatically send to all users in the role of Delivery Inspector. Each such user sees and decides only about the distribution of costs related to the cost center, for which he or she is responsible. 
Approving the completed form is equivalent to confirmation the correctness of delivery with the cost document and approvment of costs assigned to cost centers. Confirmation of the task leads to the next step of the process: Improving the document or Financial acceptance.

The Improving the document task is carried out at the moment when at least one cost center item is not accepted.

The Financial Acceptance task is implemented at the moment when all cost center positions are approved.

The Financial Acceptance task allows you to verify and accept the cost sharing.

Approval of the completed form is equivalent to financial acceptance of costs assigned to cost centers. Approving the task leads to the next step of the process: Improving the document, Management cceptance, Accounting the cost document or ending the process.

The Improving the document task is carried out when the document is sent back for improvement by the mailroom.

The process ends when the document is rejected.

The Management cceptance task is implemented at the moment when at least one cost center position exceeds the planned limit.

The Accounting the cost document is carried out when the document is approved, and the limit has not been exceeded at any of the cost centers.

The Improving the document task allows to improve the data of the cost document and the cost sharing proposed during the registration.

The task automatically goes to the list of tasks of the person appearing in the role of the mailroom amployee.

Approving the completed form is equivalent to improving the cost document. The form can not be approved until the net sum of costs assigned to individual cost centers will not coincide with the net value of the cost document.

The Management cceptance task allows the board to verify the document.

The task is automatically placed on the list of tasksfor all users appearing in the role of the board at a time when at least one cost center will exceed the limit.
Approving the task will take you to the next step of the process: Financial acceptance or Accounting the cost document.

The Financial Acceptance task is implemented when the board sends back the document for improvement.

The Accounting the cost document task is carried out when the document is verified positively.

The Financial acceptance task allows the document to be verified by accounting and the payment to be issued within the required payment deadline.

The task is automatically placed on the list of tasks for all users who are in the accounting role. The task is run in case of positive verification by the financial department and the management board.

The task handling results in displaying a form consisting of the following sections:

a. Registration details of the cost invoice.

b. Seller details.

c. Cost document data.

d. Operational allocation of costs.

e. Financial acceptance.

f. Management acceptance.

g. Accounting.

Approval of the completed form is equivalent to the acceptance of documents by the accountants and causes the transition to the next step of the process, which is the Sending to the ERP system.

After the completion of the Sending to the ERP system task the process is finalized.

\section{System architecture}

The logical architecture diagram shows interfaces for data exchange between particular elements of the business process management system and the database. The visualization module for the complete history of process execution is one of the components of the system. All data generated by the visualization module are sent to the archive module. The data collected by the archive module are stored in the database of the archive module, which constitutes a component of the database of the entire workflow system. 


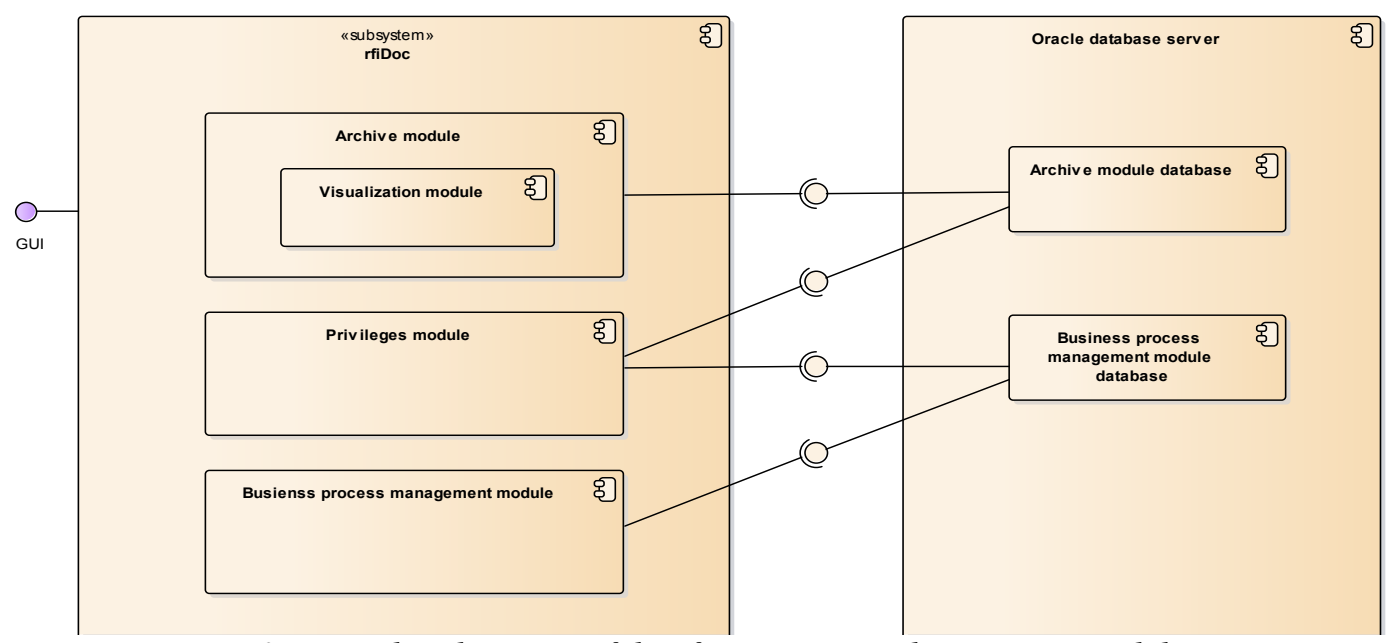

Figure 3. Logical architecture of the rfiDoc system - division into modules

The diagram shows other modules that have significant impact on the work with the rental company processes. The data gathered by particular modules are stored in the database of the system.

The module for managing access to the documents uses the database of the archive module as well as the database of the module for handling business processes. The module for handling business processes uses only the data collected in the database dedicated to such component of the system. Additionally, the system has a graphical user interface, which allows to use any of the above-mentioned modules.

\section{Conclusions}

The article outlines the BPMN diagrams of the rental company processes. The above-mentioned dynamic processes [25] were automated in the Aurea BPM system and implemented.

While using the aforesaid processes, the processes were adjusted and amended a number of times to achieve the final form as described herein. The work experience with the processes allowed to draw the above conclusions.

The BPMS systems are perfect for automation of not only core and production business processes [19]. It is also the implementation of back-office processes that plays key role in the operations of an enterprise.

The back-office processes are subject to change and optimization as often as the production processes. The process parameters and their KPIs may be determined for the back-office processes to the same degree as for the production processes. It allows to efficiently implement the systems for assessing the progress of the processes and hence suggest changes and improvements in terms of their execution.

The companies which use BPMS systems instead of ERP systems to handle back-office processes are characterized by more freedom of adapting their activities to the ever-changing market conditions. The level of satisfaction of employees and managerial staff with the applied IT systems is much higher in case of flexible BPMS systems than ERP system, in case of which any modifications are more time- and costconsuming.

The aim for future works and the direction for the research is to describe the way the presented models might be automatically converted into working application.

\section{Acknowledgements}

This work was created as a result of the project number. RPMA.01.02.00-14-5748/16-00 financed by EU.

\section{References}

1. T. Nowicki, R. Waszkowski, A. Saniuk, Business process analysis of a foodborne outbreak investigation mobile system. In. IV International Conference on Modern Technologies in Industrial Engineering (ModTech 2016), Iasi, Romania, 15-18 June 2016, IOP Conference Series: Materials Science and Engineering Volume 145 (Eds.: Cohal V. et al.), Bristol : Institute of Physics, 2016, s. 864-868, ISBN: 978-1-5108-2912-1

2. M. Jasiulewicz-Kaczmarek, A. Saniuk, T. Nowicki, The maintenance management in the macroergonomics context, Advances in Social \& Occupational Ergonomics vol 487, (2017), Springer Series, Advances in Intelligent Systems and Computing, Goossens R.H.M. (Ed.), pp. 35-46, ISBN 978-3-319-41688-5

3. R. Waszkowski, T. Nowicki, M. Kiedrowicz, Classified Document Flow Management, in Advances in Social and Occupational Ergonomics: Proceedings of the AHFE 2017, July 17-21, (2017), The Westin Bonaventure Hotel, Los Angeles, California, USA (Ed. Richard H.M.Goossens) ISSN 2194-5357, DOI 10.1007/978-3-319-60828-0, Springer International Publishing AG 2018, pp. 6271, Series: Advanced in Intelligent Systems and Computing No 605, ISBN 978-3-319-60827-3 
4. W. van der Aalst, M. van H. Kees, Workflow Management, Models, Methods and Systems, The MIT Press Cambridge, (2002).

5. H. Jonkers, H.M. Franken, Quantitative modeling and analysis of business processes, Simulation in Industry, 8th European Simulation Symposium, vol.I, p.175-179, (1996).

6. L. Tarumyan, Timing analysis for workflow processes, 17th European Simulation Symposium and Exhibition Within I3M'05 International Mediterranean Modeling Multiconference, p. 51-57, (2005).

7. W. van der Aalst, J. Desel, E. Kindler, On the semantics of EPCs: A vicious circle, Workshop on EPK, p. 7-18, (2003).

8. J. Koehler, R. Hauser, Untangling unstructured cyclic flows - a solution based on continuations, 6th Int. Conference on Cooperative Information Systems CoopIs, Springer LNCS 3290, p. 121-138, (2004).

9. L. Tarumyan, A System of performance characteristics analysis for business processes, CSIT2011 Eighth International Conference on Computer Science and Information technologies, p. 198-201, (2011).

10. F. Dirk, C. Favre, B. Jobstmann, J. Koehler, N. Lohmann, H. Völzer, K. Wolf, Instantaneous soundness checking of industrial business process models, 7th Int. Conference on Business Process Management, Springer LNCS 5701, p. 278-293, (2009).

11. J. Cardoso, A. Sheth, J. Miller, Workflow quality of service, International Conference on Enterprise Integration and Modeling Technology and International Enterprise Modeling Conference (ICEIMT/IEMC'02), (2002).

12. J. H. Son, M. H. Kim, Analyzing the critical path for the well-formed workflow schema, Seventh International Conference on Database Systems for Advanced Applications DASFAA, p.146-147, (2001).

13. J. Eder, E. Panagos, Managing time in workflow systems, Workflow Handbook 2001, Layne Fischer ed., ISBN 0-9703509-0-2, p. 109-132, (2001).

14.F.E. Allen, J. Cocke, A program data flow analysis procedure, IBM Thomas J. Watson Research Center, (1971).

15. J. Vanhatalo, H. Volzer, F. Leymann, Faster and more focused control-flow analysis for business process models though SESE decomposition, ICSOC, Vol. 4749, p. 43-55, (2007).

16. J. Vanhatalo, H. Völzer, J. Koehler, The refined process structure tree, Data \& Knowledge Engineering, v.68 n.9, p. 793-818, (2009).

17. R. Bellman. Dynamic Programming, Princeton University Press, (1957).

$\begin{array}{llll}\text { 18. Workflow } & \text { Management } & \text { Coalition } & \text { (WfMC), } \\ \text { Workflow } & \text { Standard }- & \text { Process } & \text { Definition }\end{array}$
Interchange, Process Model. WfMC TC-1016P.Version 1.1, (1999).

19. F. Leymann, D. Roller, Production Workflow: concepts and techniques. Prentice Hall, (2000).

20. M. A Schaefer, Mathematical Theory of Global Program Optimization. Prentice-Hall, (1973).

21. P. Raulefs, S. Shoukourian, L. Tarumyan, V Matevosyan, Determination of critical paths in hammock type processes, HPC'2003, SCS International Advanced Simulation Technologies Conference ASTC'2003, p. 241-246, (2003).

22. K. Grzybowska, G. Kovács, The modelling and design process of coordination mechanisms in the supply chain, Journal of Applied Logic, 24, pp. 2538, 2017, DOI: 10.1016/j.jal.2016.11.011

23. E. Chlebus, A. Burduk, A. Kowalski, Concept of a Data Exchange Agent System for Automatic Construction of Simulation Models of Manufacturing Processes, Hybrid Artificial Intelligent Systems, Part II, Lecture Notes in Artificial Intelligence, 6th International Conference on Hybrid Artificial Intelligence Systems (HAIS 2011), SN 0302-9743, BN 978-3-642-21221-5, WOS:000297712800046

24. R. Waszkowski, M. Kiedrowicz, T. Nowicki, K. Worwa, Customer service processes automation in administrative office with RFID tagged documents, Fourth International Conference on Mathematics and Computers in Sciences and in Industry, pp. 224-233, DOI 10.1109/MCSI.2017.46 (2017).

25. M. Kiedrowicz, Dynamic business process in workflow systems, MATEC Web of Conferences, vol.125,DOl:10.1051/ $\mathrm{m}$ atecconf/ 201712 502014 Greece (2017). 